\title{
No cumulative effects for one or two previous concussions
}

\author{
G L Iverson, B L Brooks, M R Lovell, M W Collins
}

Br J Sports Med 2006;40:72-75. doi: 10.1136/bjsm.2005.020651

Background: Sports medicine clinicians and the general public are interested in the possible cumulative effects of concussion.

Objective: To examine whether athletes with a history of one or two previous concussions differed in their preseason neuropsychological test performances or symptom reporting.

See end of article for authors' affiliations Method: Participants were 867 male high school and university amateur athletes who completed preseason testing with ImPACT version 2.0. They were sorted into three groups on the basis of number of previous concussions. There were 664 athletes with no previous concussions, 149 with one previous concussion, and 54 with two previous concussions. Multivariate analysis of variance was conducted using the verbal memory, visual memory, reaction time, processing speed, and postconcussion symptom composite scores as dependent variables and group membership as the independent variable.

.....................

Correspondence to:

Dr lverson, Department of

Psychiatry, University of

British Columbia, 2255

Wesbrook Mall,

Vancouver, BC V6T 2A1,

Canada; giverson@

interchange.ubc.ca

Accepted 12 July 2005
Results: There was no significant multivariate effect, nor were there any significant main effects for individual scores. There was no measurable effect of one or two previous concussions on athletes' preseason neuropsychological test performance or symptom reporting.

Conclusion: If there is a cumulative effect of one or two previous concussions, it is very small and undetectable using this methodology.
C oncussions are fairly common in American football ${ }^{1-3}$ and other sports. ${ }^{4-11}$ Moreover, there is evidence that some concussions go unrecognised. ${ }^{12}$ A single concussion is typically a self limiting injury, with symptoms resolving and neuropsychological recovery occurring in less than two weeks for most athletes. ${ }^{4}{ }^{13-18}$ However, high school and college football players with a previous concussion are at increased risk of a future concussion. ${ }^{19}{ }^{20}$ A central concern for athletes, families, coaches, athletic trainers, and sports medicine clinicians is the possibility of long lasting, or permanent, brain damage or dysfunction resulting from multiple concussions.

There is gradually accumulating evidence that a history of three or more concussions is associated with long term changes in neurophysiology, ${ }^{21}$ subjective symptoms, ${ }^{21}{ }^{22}$ and neuropsychological test performance ${ }^{22}$ in some athletes. The presumed changes in a subset of athletes are sufficient to result in statistically significant group differences. Moreover, athletes with three or more concussions are at increased risk of a future concussion, ${ }^{19}$ have worse on-field presentations of their next concussion, ${ }^{23}$ have greater acute changes in memory performance, ${ }^{22}$ and are more likely to have slowed recovery. ${ }^{19}$ The findings to date on three or more concussions should be considered preliminary, provocative, and suggestive. However, much additional research is needed because the aforementioned studies all have significant limitations in terms of methodology, generalisability, or both.

The literature on lingering effects of two previous concussions is mixed. With regard to possible long term effects, some researchers have reported significant findings, ${ }^{24}$ others have not, ${ }^{25}$ and others have equivocal results. For example, Moser and $S_{\text {chat }}{ }^{26}$ reported that athletes with a recent concussion differed from athletes with zero or one previous concussions on neuropsychological testing, but they did not differ from athletes with two or more previous concussions. However, athletes with two or more concussions did not differ from athletes with zero or one previous concussion, making the overall conclusions somewhat equivocal. Notably, the small sample sizes and Scheffe post hoc comparisons reduced the likelihood of finding significant differences.
Therefore, overall, the possible long term effects of two previous concussions are unclear. There is, however, preliminary evidence that athletes with two previous concussions have slower recovery times. ${ }^{19}$

Most of the literature on subconcussive blows to the head, such as those associated with heading the soccer ball, one or more boxing matches, or springboard diving generally suggest no obvious adverse neuropsychological ${ }^{97-29}$ or balance effects. ${ }^{30}$ However, some researchers have reported neuropsychological decrements ${ }^{31}$ or temporary adverse effects on subjective symptoms $\mathrm{s}^{32}$ associated with heading the soccer ball. Commonsense and empirical evidence suggest that a career in boxing will probably result in obvious ${ }^{33-38}$ or subtle ${ }^{39}$ damage to the structure and function of the brain. However, a least one prospective study ${ }^{40}$ and several other studies have not confirmed this ${ }^{41}{ }^{42}$ or have reported mixed or equivocal results. ${ }^{43} 44$

It will take many studies over many years to reach reasonably definitive conclusions about the short, medium, and long term cumulative effects of concussion, and who is at greatest risk. This study represents one small step in that direction. The preseason neuropsychological test performances and subjective symptom reporting of amateur athletes with zero $(\mathrm{n}=664)$, one $(\mathrm{n}=149)$, or two (n $=54$ ) previous concussions were compared. It was hypothesised that athletes with a history of two concussions, as a group, would show small differences on one or more outcome measures from athletes with no previous concussions.

\section{METHOD}

\section{Participants}

Participants were 867 male high school and university athletes who completed preseason testing with ImPACT version 2.0. Their mean (SD) age was 17.7 (2.3) years (range 13-22) and their mean (SD) education was 11.3 (2.0) years. The breakdown of athletes by sport was as follows: American football $86.7 \%$, ice hockey $9.6 \%$, soccer $2.3 \%$, and other sports $1.4 \%$. Participants were sorted into three groups on the basis of number of previous self reported concussions. Athletes were simply asked, by computerised questioning, whether 
they had sustained a previous concussion. If so, they recorded the number of previous concussions. There were 664 athletes with no previous concussions, 149 with one, and 54 with two. The breakdown of athletes by group and education level was as follows: no previous concussions, 51\% high school, $49 \%$ university; one previous concussion, 38\% high school, $62 \%$ university; two previous concussions, 33\% high school, $67 \%$ university. The breakdown of athletes by group and by sport was as follows: no previous concussions, American football $86 \%$, ice hockey $10 \%$, soccer $3 \%$, and other sports $1 \%$; one previous concussion, American football $91 \%$, ice hockey $7 \%$, soccer $1 \%$, and other sports $1 \%$; two previous concussions, American football $85 \%$, ice hockey $11 \%$, and soccer $4 \%$. Unfortunately, no information was available in the database on the time since the previous concussions or their severity. Given that the baseline testing was preseason, it is reasonable to assume that the athletes were not suffering from a recent concussion.

\section{Measure}

Version 2.0 of ImPACT is a brief computer administered neuropsychological test battery that consists of six individual test modules which measure aspects of cognitive functioning including attention, memory, reaction time, and processing speed. Each test module may contribute scores to multiple composite scores. Four composite scores were used for this study. In general, the test battery is designed to yield multiple types of information within a brief period of time. The verbal memory composite score represents the average percentage correct for a word recognition paradigm, a symbol number match task, and a letter memory task with an accompanying interference task. These tests are conceptually similar to traditional verbal learning (word list) tasks and the auditory consonant trigrams test-that is, the Brown-Peterson short term memory paradigm-although the information is presented visually on the computer, not orally by an examiner. The visual memory composite score comprises the average percentage correct scores for two tasks: a recognition memory task that requires the discrimination of a series of abstract line drawings, and a memory task that requires the identification of a series of illuminated Xs or Os after an intervening task (mouse clicking a number sequence from 25 to 1). The first test taps immediate and delayed memory for visual designs and the second test measures short term spatial memory (with an interference task). The reaction time composite score represents the average response time (in milliseconds) on a choice reaction time, a go/no-go task, and the previously mentioned symbol match task (which is similar to a traditional digit symbol task). The processing speed composite represents the weighted average of three tasks that are performed as interference tasks for the memory paradigms. In addition to the cognitive measures, ImPACT also contains a postconcussion symptom scale which consists of 21 commonly reported symptoms-for example, headache, dizziness, "fogginess". The dependent measure is the total score derived from this 21 item scale. The reliability ${ }^{45}{ }^{46}$ and concurrent validity ${ }^{47}$ of the cognitive composite scores and the postconcussion symptom scale ${ }^{49-51}$ and the sensitivity of the battery to the acute effects of concussion ${ }^{13} 18465253$ have been examined in a number of studies.

\section{RESULTS}

The multivariate assumption of normality was violated for several of the dependent variables within each group. However, Levene's test for homogeneity of variance was not significant for any of the outcome variables. Therefore, parametric statistics were used, and non-parametric analyses were conducted for exploratory purposes. Age and education showed significant correlation ( $r=0.94$ in the total sample). There were very small but significant correlations between education and verbal memory $(r=0.07)$ and processing speed $(r=0.14)$. Moreover, a one way analysis of variance revealed a significant main effect for education across groups. Therefore education was used as a covariate.

Table 1 provides descriptive statistics for the test scores by group. Multivariate analysis of variance, with the five composite scores as dependent variables, group membership as an independent variable, and education as a covariate revealed no overall significant effects. Exploratory one way analyses of variance were conducted using verbal memory, visual memory, reaction time, processing speed, and postconcussion symptom composite scores as dependent variables and group membership as the independent variable. There were no significant main effects for group on any

\begin{tabular}{|c|c|c|c|c|c|c|}
\hline Variable/group & Median & Mean & SD & IQR & $\begin{array}{l}\text { 10th } \\
\text { centile }\end{array}$ & $\begin{array}{l}\text { 90th } \\
\text { centile }\end{array}$ \\
\hline \multicolumn{7}{|l|}{ Verbal memory } \\
\hline None & 87.9 & 87.1 & 8.3 & $82.0-93.4$ & 76.0 & 97.2 \\
\hline One & 87.0 & 87.1 & 7.6 & $82.3-93.4$ & 76.9 & 97.2 \\
\hline Two & 86.1 & 86.1 & 7.3 & $81.3-91.8$ & 76.6 & 95.1 \\
\hline \multicolumn{7}{|l|}{ Visual memory } \\
\hline None & 78.0 & 77.3 & 11.8 & $69.4-86.1$ & 61.1 & 92.0 \\
\hline One & 77.8 & 77.0 & 11.5 & $70.4-84.7$ & 61.0 & 92.0 \\
\hline Two & 76.4 & 76.4 & 11.4 & $70.6-83.3$ & 59.0 & 91.3 \\
\hline \multicolumn{7}{|l|}{ Processing speed } \\
\hline None & 36.4 & 36.6 & 6.8 & $32.4-40.7$ & 28.3 & 45.4 \\
\hline One & 37.8 & 37.2 & 6.8 & $32.0-41.5$ & 28.2 & 46.4 \\
\hline Two & 38.7 & 36.8 & 6.6 & $31.8-41.3$ & 27.6 & 44.6 \\
\hline \multicolumn{7}{|l|}{ Reaction time* } \\
\hline None & 0.550 & 0.559 & 0.075 & $0.600-0.510$ & 0.650 & 0.480 \\
\hline One & 0.550 & 0.557 & 0.068 & $0.600-0.510$ & 0.640 & 0.480 \\
\hline Two & 0.550 & 0.563 & 0.068 & $0.583-0.520$ & 0.645 & 0.485 \\
\hline \multicolumn{7}{|l|}{ Total symptoms } \\
\hline None & 2.0 & 4.9 & 7.9 & $0-6$ & 0 & 14 \\
\hline One & 2.0 & 5.3 & 8.7 & $0-6$ & 0 & 19 \\
\hline Two & 2.0 & 5.7 & 8.5 & $0-9$ & 0 & 18 \\
\hline
\end{tabular}

None, No previous concussions ( $\mathrm{n}=664$ ); One, one previous concussion ( $\mathrm{n}=149$ ); Two, two previous concussions ( $\mathrm{n}=54)$.

$I Q R$, Interquartile range.

*Reaction time is in seconds; faster (lower numbers) is better. This is reflected in the IQR and the 10th and 90th centiles. 
What is already known on this topic

- There is accumulating evidence that a history of three or more concussions is associated with lingering adverse effects in some amateur athletes

- The literature on lingering or cumulative effects from one or two previous concussions is mixed

variable. Exploratory pairwise comparisons using $t$ tests uncorrected for familywise error also did not yield any significant effects attributable to concussion history. Exploratory non-parametric analyses (Kruskal-Wallis) also revealed no significant differences on any test score attributable to concussion history.

The 10th centile for the never concussed group was selected as a cut-off score for unusually poor performance for each dependent measure. Choosing cut-off scores can be somewhat arbitrary. For this study, we conceptualised the performance of $80 \%$ of healthy, never concussed athletes as "broadly normal"- that is, $80 \%$ of these athletes score between the 10th and 90th centile. Scores below the 10th centile can be considered unusually low, and scores above the 90th centile unusually high. The percentages of athletes with one previous concussion who scored at or below the 10th centile were as follows: verbal memory $5 \%$, visual memory $11 \%$, processing speed $10 \%$, reaction time $8 \%$, total symptoms $13 \%$. The percentages of athletes with two previous concussions who scored at or below the 10th centile were as follows: verbal memory $9 \%$, visual memory $11 \%$, processing speed $11 \%$, reaction time $9 \%$, total symptoms $9 \%$.

\section{DISCUSSION}

The purpose of this study was to determine if athletes with one or two previous concussions differed from athletes with no previous concussions on baseline preseason symptom reporting or cognitive test performance. The obvious strength of this study is the very large sample size. Several methodological weaknesses, however, limit the usefulness and generalisability of these findings. Firstly, all athletes were young men; thus the results cannot be generalised to young women. Secondly, the cross sectional study design combined with the use of group based inferential statistics might have limited the ability to detect subtle cumulative effects in a small subset of athletes. Thirdly, the number of previous concussions was based on athlete self report. Information on time since injury and severity of injury was not available. Therefore issues such as the grade of concussion, duration of time between concussion, and time taken to return to play could not be analysed statistically. This, obviously, is a major limitation. Finally, because the testing was carried out preseason, if an athlete had obvious lingering effects from a previous concussion he might not have undergone baseline testing because he might not be participating in sport that season. These limitations are not unique to this study. Limited generalisability to female athletes, ${ }^{19}{ }^{21-23}$ uncertain time interval between injury and testing, ${ }^{26}$ and unknown past injury severity are found in other studies of cumulative effects of concussions.

With the aforementioned limitations in mind, this study revealed no measurable effect of one or two previous concussions on athletes' preseason neuropsychological test performance or symptom reporting. The groups were carefully examined in multiple ways, with multiple statistical tests (primary and exploratory), and no significant effects or trends were found. Therefore these results suggest that if
What this study adds

- Groups of athletes with one or two previous concussions were carefully examined in multiple ways, with multiple statistical tests, and no significant effects or trends were found on preseason neuropsychological test performance or symptom reporting

- These results suggest that if there is a cumulative effect of one or two previous concussions, it is probably very small

there is a cumulative effect of one or two previous concussions, it is probably very small.

The failure to detect possible persisting problems from one or two previous concussions is probably not due to inadequate sensitivity of the computerised screening measure. Cognitive decrements associated with mild depression, ${ }^{54}$ attention deficit/hyperactivity disorder, ${ }^{55}$ and, of course, sports concussion have been reported in studies using this screening battery. The following are some recent examples of the sensitivity of ImPACT to concussions in athletes: (a) high school athletes with grade I ("ding") concussions showed a decline in memory one to three days after the injury followed by a return to baseline at 5-10 days after the injury ${ }^{13} ;(b)$ concussed athletes reporting headaches one week after the injury had slower reaction times and lower memory scores than concussed athletes who did not report headaches ${ }^{53} ;(c)$ concussed athletes reporting perceived "fogginess" one week after the injury had slower reaction times, reduced processing speed, and lower memory scores than concussed athletes who did not report fogginess. ${ }^{52}$

Similar to the present study, Macciocchi et $a l^{25}$ and Moser and Schatz $^{26}$ did not find obvious cumulative effects of concussions on neuropsychological functioning or symptom reporting. However, small sample sizes and equivocal results ${ }^{26}$ make it difficult to accurately interpret these studies. On the other hand, results from other studies suggest that there are cumulative effects from three or more concussions on the severity of on-field markers ${ }^{23}$ and recovery from symptoms, ${ }^{19}$ as well as neurophysiological ${ }^{21}$ and neuropsychological $^{22}$ functioning. Clearly, more research is required before definitive conclusions can be drawn and evidence based practice guidelines, which are very much needed, ${ }^{56}$ can be established.

\section{Authors' affiliations}

G L Iverson, Department of Psychiatry, University of British Columbia, Vancouver, Canada

B L Brooks, Riverview Hospital, Coquitlam, British Columbia, Canada M R Lovell, M W Collins, University of Pittsburgh Medical Center, Pittsburgh, PA, USA

Competing interests: none declared

\section{REFERENCES}

1 Schulz MR, Marshall SW, Mueller FO, et al. Incidence and risk factors for concussion in high school athletes, North Carolina, 1996-1999. Am J Epidemiol 2004; 160:937-44.

2 Pellman EJ, Powell JW, Viano DC, et al. Concussion in professional football: epidemiological features of game injuries and review of the literature. Part 3. Neurosurgery 2004;54:81-94; discussion 94-6.

3 Powell JW, Barber-Foss KD. Traumatic brain injury in high school athletes. JAMA 1999;282:958-63.

4 Bleiberg J, Cernich AN, Cameron K, et al. Duration of cognitive impairment after sports concussion. Neurosurgery 2004;54:1073-78; discussion 1078-80.

5 Hinton-Bayre AD, Geffen G, Friis P. Presentation and mechanisms of concussion in professional Rugby League Football. J Sci Med Sport 2004;7:400-4. 
6 Koh JO Cassidy JD. Incidence study of head blows and concussions in competition taekwondo. Clin J Sport Med 2004; 14:72-9.

7 Koh JO, Cassidy JD, Watkinson EJ. Incidence of concussion in contact sports: a systematic review of the evidence. Brain Inj 2003;17:901-17.

8 Marshall SW, Spencer RJ. Concussion in rugby: the hidden epidemic. J Athl Train 2001;36:334-8.

9 Rutherford A, Stephens R, Potter D. The neuropsychology of heading and head trauma in Association Football (soccer): a review. Neuropsychol Rev 2003:13:153-79.

10 Wennberg RA, Tator $\mathrm{CH}$. National Hockey League reported concussions, 1986-87 to 2001-02. Can J Neurol Sci 2003;30:206-9.

11 Delaney JS. Head injuries presenting to emergency departments in the United States from 1990 to 1999 for ice hockey, soccer, and football. Clin J Sport Med 2004; 14:80-7.

12 McCrea M, Hammeke T, Olsen G, et al. Unreported concussion in high school football players: implications for prevention. Clin J Sport Med 2004; 14:13-17.

13 Lovell MR, Collins MW, Iverson GL, et al. Grade 1 or "ding" concussions in high school athletes. Am J Sports Med 2004;32:47-54.

14 Macciocchi SN, Barth JT, Alves W, et al. Neuropsychological functioning and recovery after mild head injury in collegiate athletes. Neurosurgery 1996:39:510-14.

15 McCrea M, Guskiewicz KM, Marshall SW, et al. Acute effects and recovery time following concussion in collegiate football players: the NCAA Concussion Study. JAMA 2003;290:2556-63.

16 Pellman EJ, Lovell MR, Viano DC, et al. Concussion in professional football: neuropsychological testing. Part 6. Neurosurgery 2004;55:1290-305.

17 McCrea M, Kelly JP, Randolph C, et al. Immediate neurocognitive effects of concussion. Neurosurgery 2002;50:1032-40; discussion 1040-2.

18 Lovell MR, Collins MW, lverson GL, et al. Recovery from mild concussion in high school athletes. J Neurosurg 2003;98:296-301.

19 Guskiewicz KM, McCrea M, Marshall SW, et al. Cumulative effects associated with recurrent concussion in collegiate football players: the NCAA Concussion Study. JAMA 2003;290:2549-55.

20 Zemper, ed. Two-year prospective study of relative risk of a second cerebral concussion. Am J Phys Med Rehabil 2003;82:653-9.

21 Gaetz M, Goodman D, Weinberg H. Electrophysiological evidence for the cumulative effects of concussion. Brain Inj 2000;14:1077-88.

22 Iverson GL, Gaetz M, Lovell MR, et al. Cumulative effects of concussion in amateur athletes. Brain Inj 2004; 18:433-43.

23 Collins MW, Lovell MR, Iverson GL, et al. Cumulative effects of concussion in high school athletes. Neurosurgery 2002;51:1175-9; discussion 1180-1.

24 Collins MW, Grindel SH, Lovell MR, et al. Relationship between concussion and neuropsychological performance in college football players. JAMA 1999;282:964-70.

25 Macciocchi SN, Barth JT, Littlefield L, et al. Multiple concussions and neuropsychological functioning in collegiate football players. J Athl Train 2001;36:303-6.

26 Moser RS, Schatz P. Enduring effects of concussion in youth athletes. Arch Clin Neuropsychol 2002;17:91-100.

27 Moriarity J, Collie A, Olson D, et al. A prospective controlled study of cognitive function during an amateur boxing tournament. Neurology 2004;62:1497-502.

28 Putukian M, Echemendia RJ, Mackin S. The acute neuropsychological effects of heading in soccer: a pilot study. Clin J Sport Med 2000;10:104-9.

29 Zillmer EA. The neuropsychology of repeated 1- and 3-meter springboard diving among college athletes. App/ Neuropsychol 2003;10:23-30.

30 Mangus BC, Wallmann HW, Ledford M. Analysis of postural stability in collegiate soccer players before and after an acute bout of heading multiple soccer balls. Sports Biomech 2004;3:209-20.

31 Matser JT, Kessels AG, Lezak MD, et al. A dose-response relation of headers and concussions with cognitive impairment in professional soccer players. J Clin Exp Neuropsychol $2001 ; 23: 770-4$
32 Schmitt DM, Hertel J, Evans TA, et al. Effect of an acute bout of soccer heading on postural control and self-reported concussion symptoms. Int J Sports Med 2004;25:326-31

33 Zhang L, Ravdin LD, Relkin N, et al. Increased diffusion in the brain of professional boxers: a preclinical sign of traumatic brain injury? Am J Neuroradiol 2003;24:52-7.

34 Rabadi MH, Jordan BD. The cumulative effect of repetitive concussion in sports. Clin J Sport Med 2001;11:194-8.

35 Dale GE, Leigh PN, Luthert $P$, et al. Neurofibrillary tangles in dementia pugilistica are ubiquitinated. J Neurol Neurosurg Psychiatry 1991;54:116-8.

36 Jordan BD, Zimmerman RD. Computed tomography and magnetic resonance imaging comparisons in boxers. JAMA 1990;263:1670-4.

37 Roberts GW, Allsop D, Bruton C. The occult aftermath of boxing. J Neurol Neurosurg Psychiatry 1990;53:373-8.

38 Miele VJ, Carson L, Carr A, et al. Acute on chronic subdural hematoma in a female boxer: a case report. Med Sci Sports Exerc 2004;36:1852-5.

39 Kemp PM, Houston AS, Macleod MA, et al. Cerebral perfusion and psychometric testing in military amateur boxers and controls. J Neurol Neurosurg Psychiatry 1995:59:368-74.

40 Porter MD. A 9-year controlled prospective neuropsychologic assessment of amateur boxing. Clin J Sport Med 2003;13:339-52.

41 Haglund Y, Bergstrand G. Does Swedish amateur boxing lead to chronic brain damage? 2. A retrospective study with CT and MRI. Acta Neurol Scand 1990:82:297-302

42 Murelius O, Haglund Y. Does Swedish amateur boxing lead to chronic brain damage? 4. A retrospective neuropsychological study. Acta Neurol Scand $1991 ; 83: 9-13$.

43 Haglund Y, Persson HE. Does Swedish amateur boxing lead to chronic brain damage? 3. A retrospective clinical neurophysiological study. Acta Neurol Scand 1990;82:353-60

44 Rodriguez G, Vitali P, Nobili F. Long-term effects of boxing and judo-choking techniques on brain function. Ital J Neurol Sci 1998;19:367-72.

45 Iverson GL, Lovell MR, Collins MW, et al. Tracking recovery from concussion using ImPACT: applying reliable change methodology. Arch Clin Neuropsychol 2002;17:770

46 Iverson GL, Lovell MR, Collins MW. Interpreting change on ImPACT following sport concussion. Clin Neuropsychol 2003;17:460-7.

47 Iverson GL, Lovell MR, Collins MW. Validity of ImPACT for measuring processing speed following sports-related concussion. J Clin Exp Neuropsychol 2005;27:683-9.

48 Iverson GL, Franzen MD, Lovell MR, et al. Construct validity of ImPACT in athletes with concussions. Arch Clin Neuropsychol 2004;19:961-2.

49 Iverson GL, Gaetz M. Practical considerations for interpreting change following concussion. In: Lovell MR, Echemendia RJ, Barth J, et al, eds. Traumatic brain injury in sports: an international neuropsychological perspective. Lisse, the Netherlands: Swets-Zeitlinger, 2004:323-56.

50 Lovell MR, Iverson GL, Collins MW, et al. Measurement of symptoms following sports-related concussion: reliability and normative data for the postconcussion scale. Appl Neuropsychol 2005; in press.

51 Janusz JA, Gioia GA, Gilstein K, et al. Construct validity of the ImPACT postconcussion scale in children. Br J Sports Med 2004;38:659.

52 Iverson GL, Gaetz M, Lovell MR, et al. Relation between fogginess and outcome following concussion. Arch Clin Neuropsychol 2002;17:769-770.

53 Collins MW, Iverson GL, Lovell MR, et al. On-field predictors of neuropsychological and symptom deficit following sports-related concussion. Clin J Sport Med 2003;13:222-9.

54 Iverson GL, Moseley JV. Sensitivity of computerized neuropsychological screening in depressed university students. Toronto: American Psychological Association, 2003.

55 Iverson GL, Strangway CL. Computerized neuropsychological screening of adolescents with ADHD, Dallas, TX, National Association of School Psychologists, 2004

56 McCrory P. Treatment of recurrent concussion. Curr Sports Med Rep $2002 ; 1: 28-32$ 